\title{
Use of guest speakers in nursing education: an integrative review of multidisciplinary literature
}

This article was published in the following Dove Press journal:

Advances in Medical Education and Practice

\author{
Ping Zou' \\ Winnie Sun ${ }^{2}$ \\ Sunny G Hallowell ${ }^{3}$ \\ Yan Luo ${ }^{4}$ \\ Charlotte Lee ${ }^{5}$ \\ $\mathrm{Li} \mathrm{Ge}{ }^{6}$
}

'School of Nursing, Nipissing University, Toronto, Ontario M6J 3S3, Canada;

${ }^{2}$ Faculty of Health Sciences, University of Ontario Institute of Technology, Oshawa, Ontario LIH 7K4, Canada; ${ }^{3} \mathrm{M}$. Louise Fitzpatrick College of Nursing, Villanova University, Villanova, PA, 19085, USA;

${ }^{4}$ Faculty of Nursing, Health Science Center, Xi'an Jiaotong University, Xi'an, Shaanxi, 71006I, People's Republic of China; ${ }^{5}$ Daphne Cockwell School of Nursing, Ryerson University, Toronto, Ontario M5B 2K3, Canada; ${ }^{6} \mathrm{School}$ of Nursing, Fujian University of Traditional Chinese Medicine, Fuzhou, 350I22, People's Republic of China
Correspondence: Ping Zou

School of Nursing, Nipissing University,

750 Dundas Street West, Room 209,

Toronto, Ontario M6J 3S3, Canada

$\mathrm{Tel}+$ I 4166427003

Email pingz@nipissingu.ca
Background: The purpose of this paper is to review existing literature regarding the use of guest speakers in multidisciplinary education and discuss the implication of the findings in nursing education.

Method: An integrative review including 18 papers from 13 disciplines.

Results: The evidence indicates that guest speakers can be invited by a variety of stakeholders with various motivations. Individuals from both discipline-related practical fields and academic institutions are frequently invited. Guest speakers have the ability to promote better teaching outcomes. Having a database of potential speakers decreases the work of selecting future guest speakers. Guest speakers can also be virtual with the use of guest speakers growing. A flow model of using guest speakers, including seven steps, has been articulated. Involving guest speakers promotes reciprocal benefits, where guest speakers, students, and professors have dual roles and contribute to and gain from each other.

Conclusion: Findings from multiple disciplines regarding guest speakers in higher education can inform the best possible practices and procedures in how to get the best use of guest speakers in undergraduate nursing education. However, further research and study are warranted within the discipline of nursing to produce findings directly applicable to nursing education.

Keywords: guest speaker, guest lecture, online, multi-disciplinary literature, review

\section{Introduction}

Collaboration between students and others beyond their learning community in a university is important for effective learning. The practice of using guest speakers in education is a common approach of enriching students' learning experiences in the education of many disciplines. In higher education, a guest speaker is a person invited to present or speak regarding a topic at an event where they are not the host, such as for a course or fair. ${ }^{1}$ Traditional guest speaker experiences are where a guest would interact with students in a series of collaborative activities such as presentations or seminars. With the development of technology, virtual guest speakers are becoming prevalent in university teaching. Many disciplines use guest speakers, yet there is limited literature on this topic in specific disciplines such as nursing. The summary of the findings can facilitate future learning and teaching.

Guest speakers are regularly used in nursing education. In the laboratory, clinical experts are invited to teach nursing skills, such as intravenous line management and wound care. In the university, clinical partners are invited to introduce potential practicum opportunities. In library, librarians can be invited to teach literature search and evidence evaluation. In classroom and clinical, nursing leaders are invited to share 
their leadership experiences in the field. Additionally, patients are invited as speakers to share their experiences. The use of guest speakers is essential in nursing education to foster learning beyond the classroom, to strengthen connections between schools and clinical, and to encourage multidisciplinary collaboration. $^{2}$

There is limited evidence of the process and the effectiveness of using guest speakers in nursing education. One study explored using Podcasts, which included 5-10 mins nursing researcher interviews in the Principles of Research and Evidence Based Practice online module to enhance linkage between the theoretical content and research in practice and improve the level of student support offered in a blended learning environment. These Podcasts can be considered virtual guest speakers. Findings suggested that these Podcasts increased students' understanding of research contents by creating a personal student/tutor relationship which allowed the students to be more engaged. ${ }^{3}$ Another study evaluated the feasibility, cost-effectiveness, and usefulness of a 10-min hospital leader interview video as an instructional tool in a nursing leadership course. The video was well accepted amongst students. ${ }^{2}$ There is some insufficiency in the research of guest speakers for nursing education. First, the number of studies is very limited. Second, the use of guest speakers in a classroom setting is missing. Since nursing is a practicebased profession, it is more effective to have guest speakers be physically present with the student rather than over a technological platform. Third, there are some methodology limitations in existing studies, such as low response rate in a cross-sectional survey and mainly qualitative design., ${ }^{2,3}$ The current evidence on using guest speakers in nursing education is limited and needs further research to identify and meet the specific needs of faculty, students, and guest speakers in order to promote increased learning outcomes. A systematic review which synthesizes existing knowledge in different disciplines can benefit nursing education by identifying various implementation processes, applications, and impacts surrounding the use of guest speakers.

In this paper, the $5 \mathrm{Ws}$ framework is used to formulate the research questions and guide the examination of existing literature regarding the use of guest speakers in education. The 5Ws framework is a traditional approach to explore a human-social phenomenon. This framework includes five questions starting with interrogative words such as who, what, where, when, why, and sometimes how. The answers to these questions are considered fundamental in information gathering and problem solving. ${ }^{4}$ The $5 \mathrm{Ws}$ framework has been used across time since classical antiquity and currently in journalism, management, and even computer sciences. ${ }^{5,6}$ In academic studies, this conceptual framework is used to facilitate scientific queries by asking appropriate research questions in nursing and other health care studies. ${ }^{4,7}$ In this paper, the research questions are who should invite or be a guest speaker; what should the guest present; where should the guest present; when should guest speakers be used; and how should guest speakers be used. The implications of current literature to nursing education are discussed.

\section{Methods}

The protocol and reporting of the results of this systematic review were based on the PRISMA statement. ${ }^{8}$ Literature searches on the application of guest speakers on education were conducted in various databases which included MEDLINE, ERIC, ProQuest, PsyINFO, and CINAHL. The used searching keywords were "guest speaker", "guest lecturer", "guest event”, “invited speaker", “education", “teaching", and "learning". Inclusion criteria are: articles were (a) written in English, (b) focused on the related issues of using guest speakers in education, and (c) related to postsecondary education. Due to the limited literature on this topic, articles from any year and discipline were included in this review. Exclusion criteria are: articles (a) did not have an accessible electronic text document or (b) did not have an author. The evidence of expert opinion has been included in this review. However, to count as a piece of expert opinion, the author's name, credential, and professional background needed to be ensured. 18 papers met the criteria and were selected for this review (Figure 1).

We used Critical Appraisal Skills Program Checklists as quality assessment tools to assess included articles. ${ }^{9}$ These checklists are designed to evaluate the studies as a whole, classifying their quality as low, moderate, or high. Two researchers independently evaluated each article; any discrepancies in ratings were discussed along with the guidelines until a consensus was reached. Only papers that were rated at moderate to high quality were included. Individual details of the included studies were extracted, such as authors, year of publication, study population, research design, recruitment method, sample size, sample characteristics, comparison group, outcomes, measurements, and significant findings.

\section{Results}

\section{Description of included studies}

Eighteen papers were included (Table 1). These papers come from 13 disciplines, including education (3 papers in total, 1 


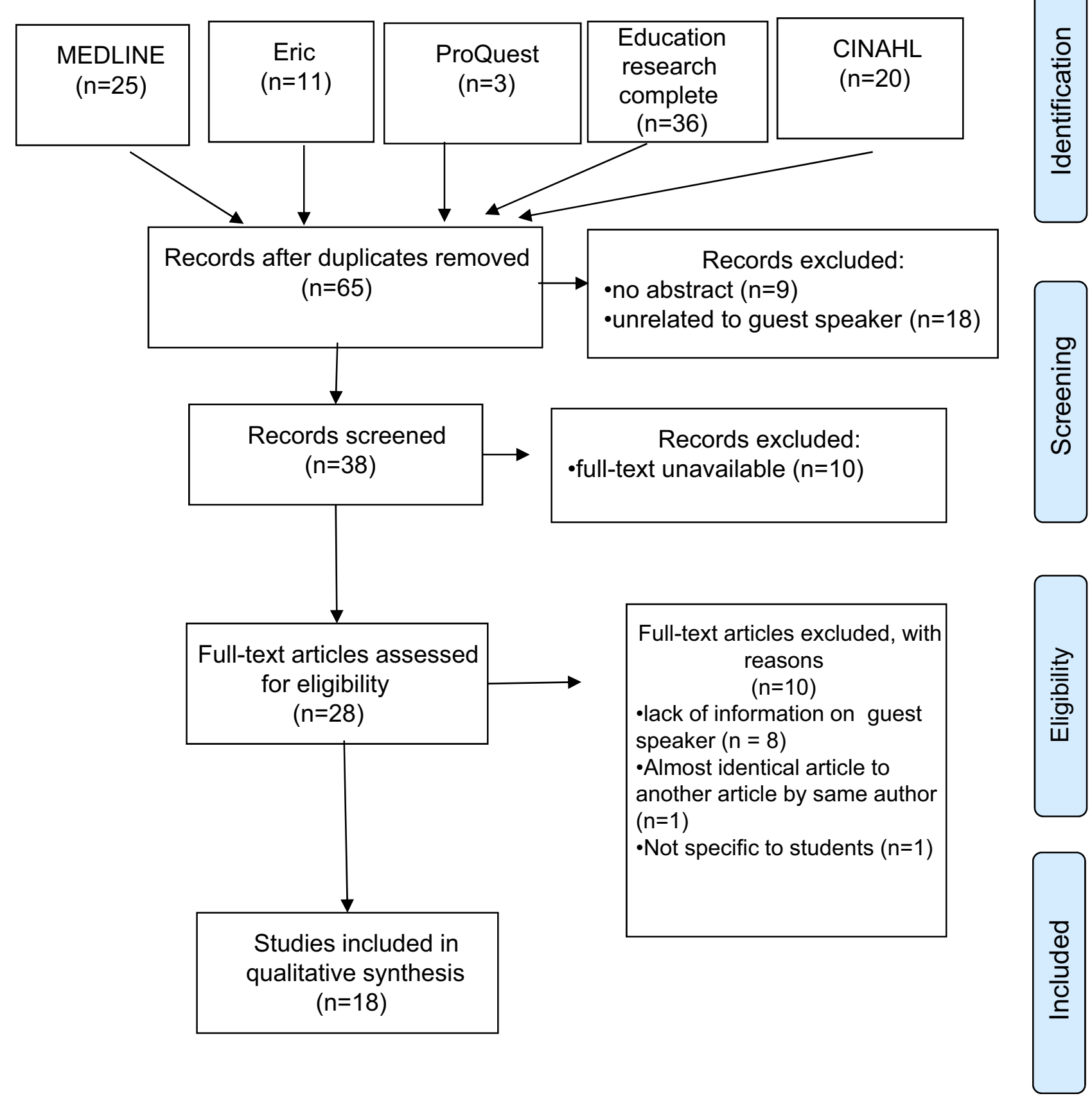

Figure I The flow diagram of study selection.

on democracy education, 1 on language, 1 on sexual health), business ( 2 papers), librarian ( 2 papers), nursing ( 2 papers), marketing, journalism, sociology, accounting, technology, hospitality and tourism, pharmacy, kinesiology, and social work. Among 18 papers, 11 (61.1\%) discussed using traditional guest speakers in classroom settings and 7 (38.9\%) explored using virtual guest speakers; 9 (50.0\%) were expert opinions, 7 (38.9\%) were descriptive or exploratory studies, 2 (11.1\%) used quasi-experimental design; 11 (61.1\%) were published on or before 2010, and 7 (38.9\%) were published after $2010 ; 16(88.9 \%)$ were written by authors in the United States and $2(11.1 \%)$ by non-American authors.

\section{Who: inviters and speakers} Who should invite guest speakers?

Although guest speakers can be invited by a variety of stakeholders with various motivations, guest speakers are usually invited by the faculty with the motivation for these 


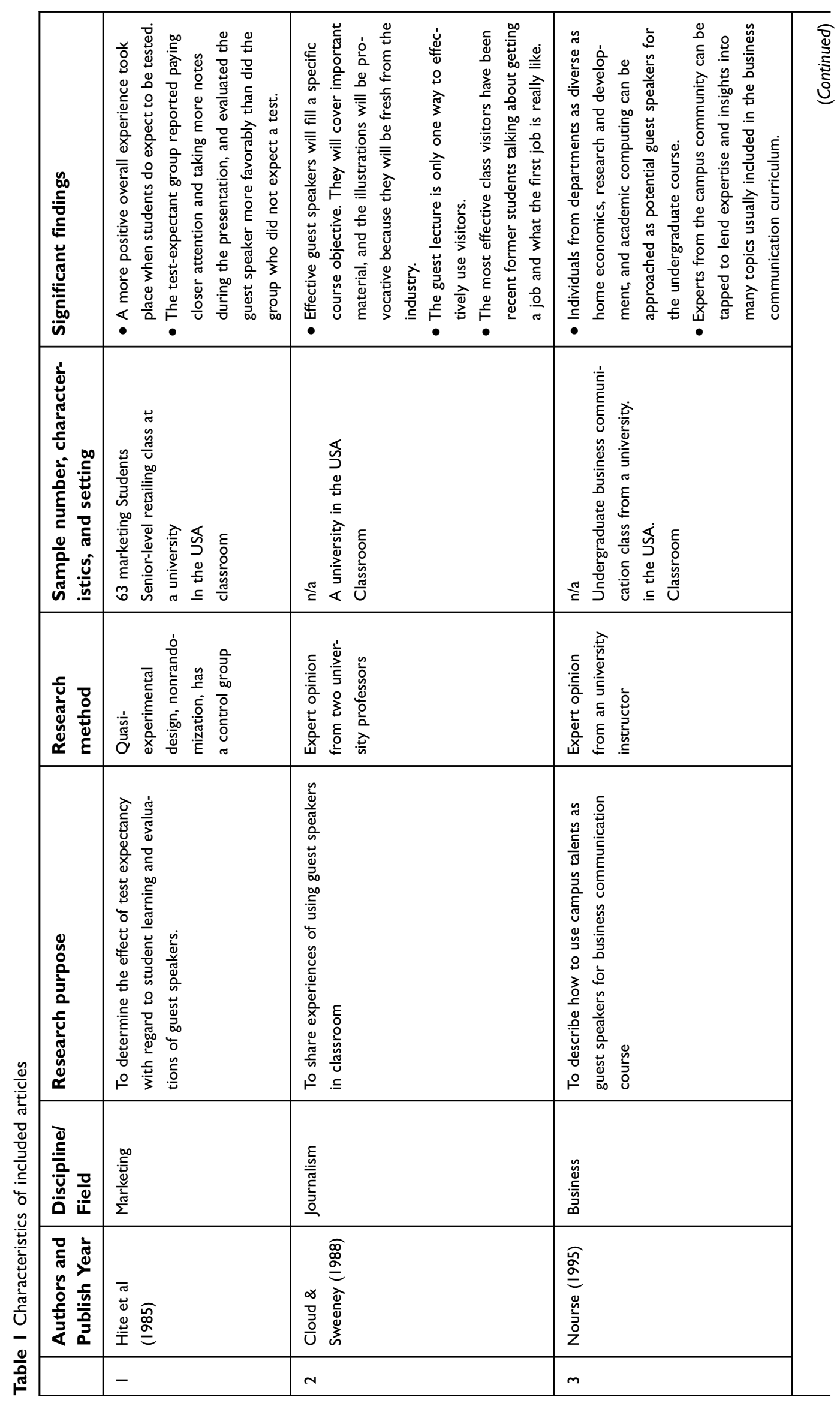




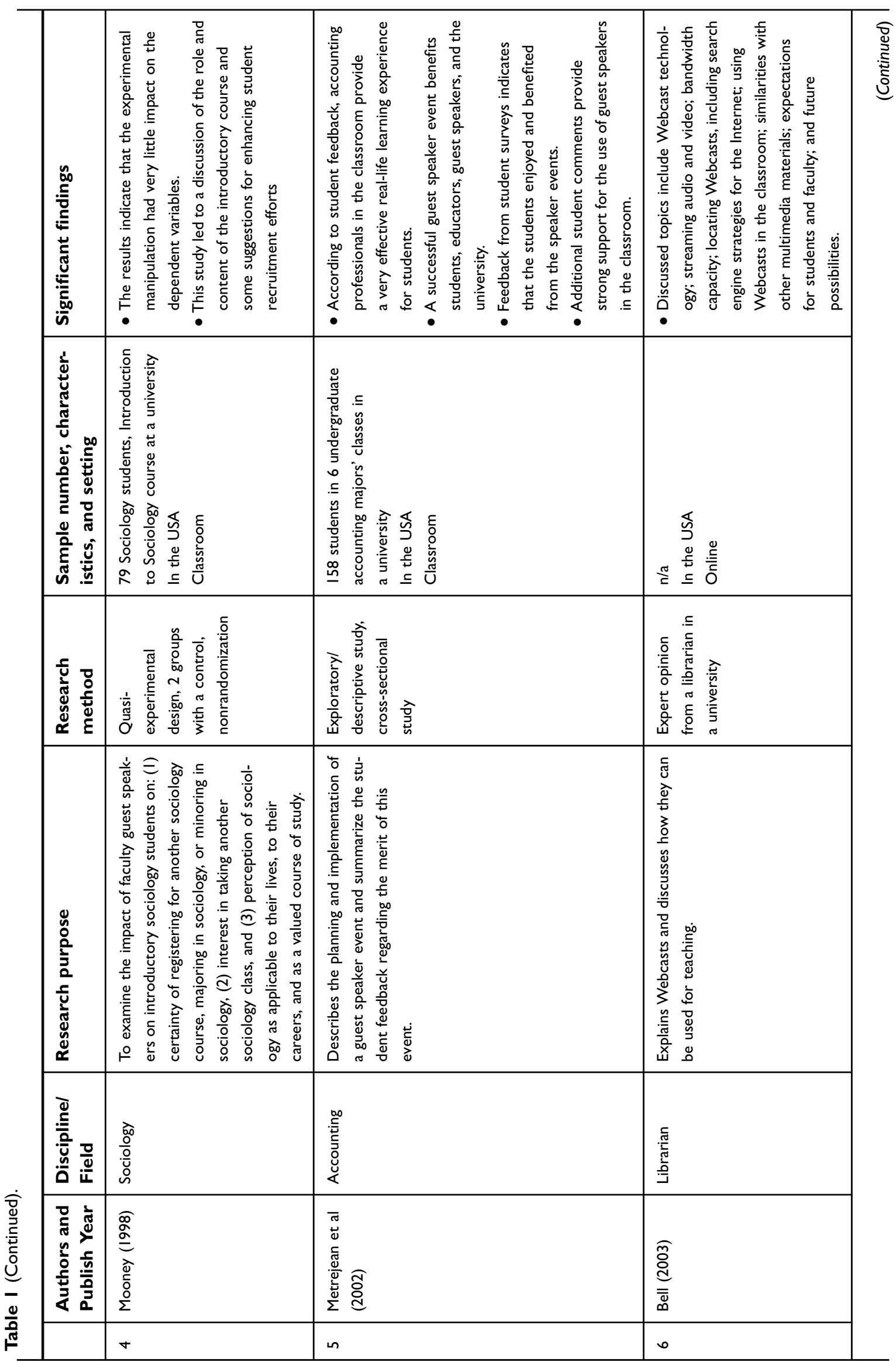




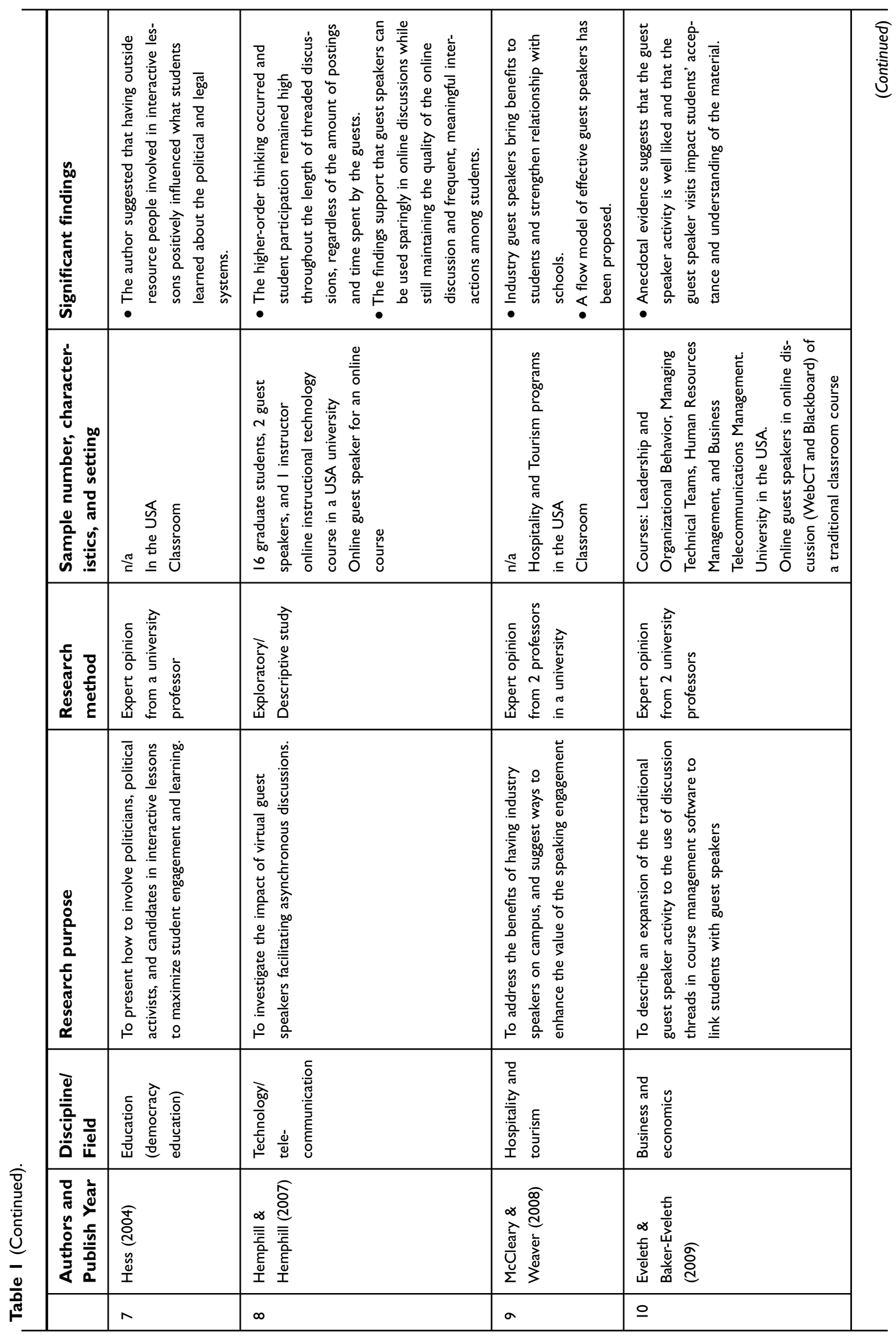




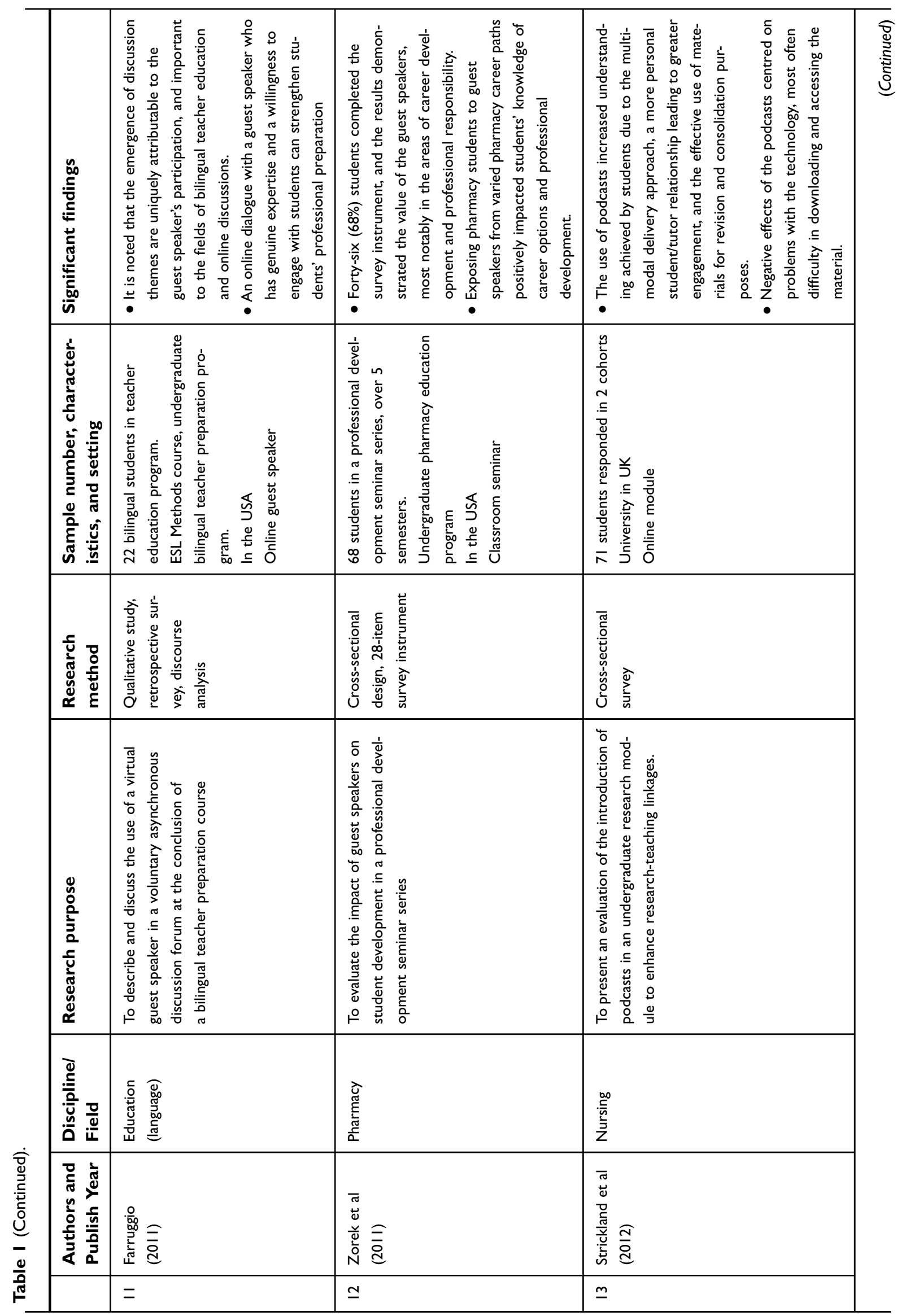




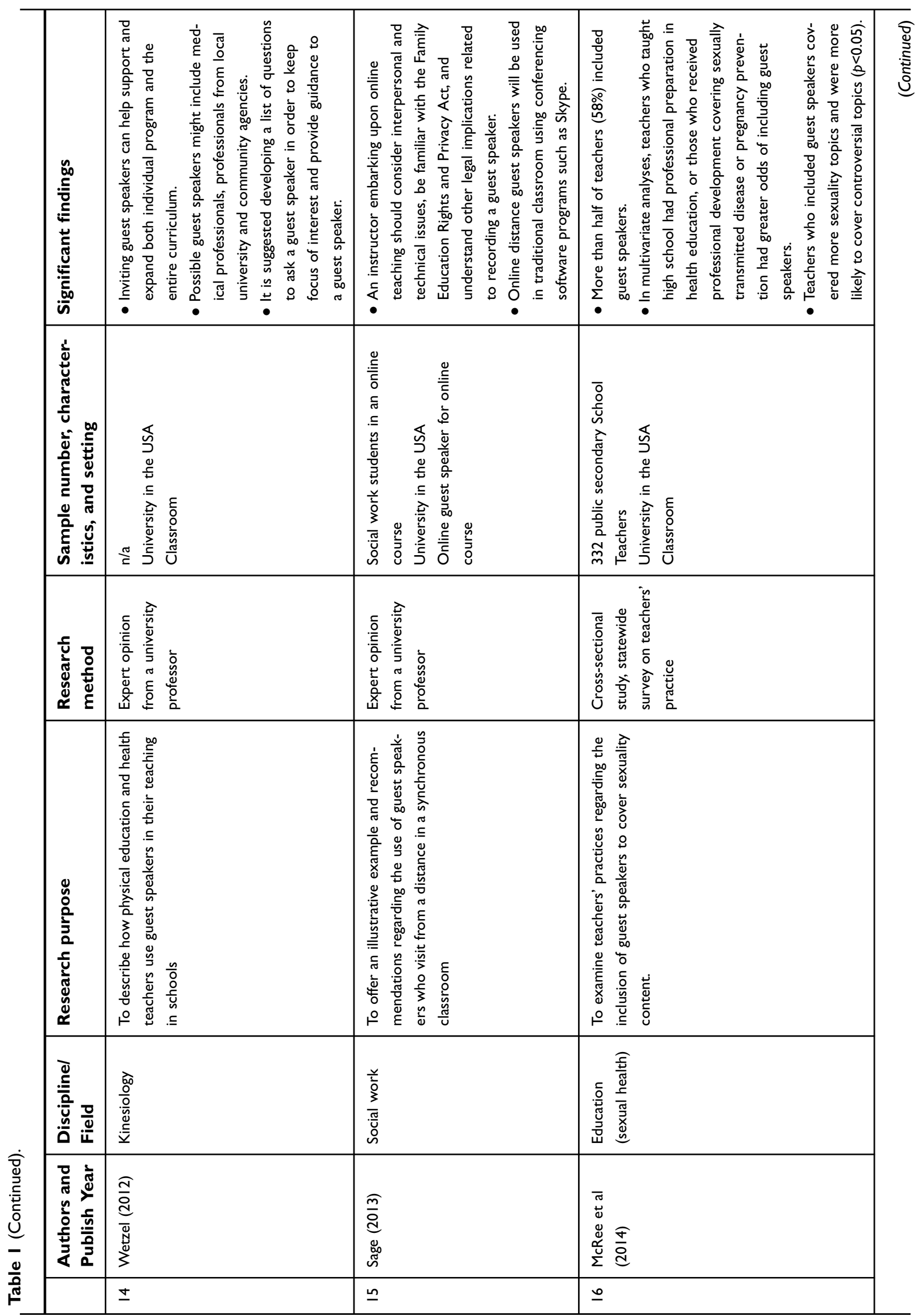




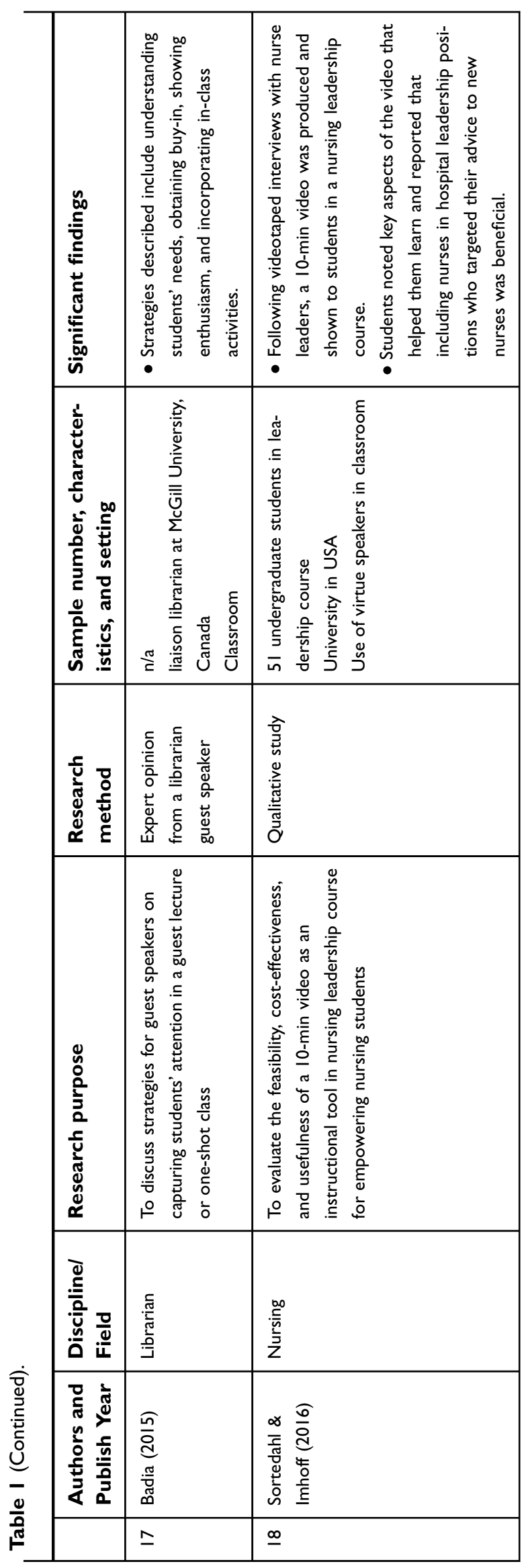


speakers to teach some course contents on behalf of the school. ${ }^{10,11}$ In addition, the faculty may also use guest speakers to build relationships with different organizations, which could lead to funding for the school, internships, and employment opportunities for students, and strong partnerships among schools, organizations, and the public. $^{10,12}$ Guest speakers may also be invited by students. There are several advantages of encouraging students to select guest speakers. Students are more likely to respect speakers chosen by themselves, granting that speaker more credibility. Guest speakers will feel honored that they were requested by the students. By allowing students choose the guest speakers, it promotes diversity of speakers from semester to semester. ${ }^{1}$ In addition, guest speakers may also request to present with the motive of gaining insight into the academic world and to communicate with students that could become potential applicants of their institution. ${ }^{12}$

\section{Who should be the guest speaker?}

Individuals from discipline-related practical fields are frequently invited to be guest speakers to expose students to professionals working in disciplines they study. Speakers can be practitioners, industry representatives, or employees working in a sector related to the course content. ${ }^{12-14}$ Guest speakers from the field may also be school alumni with varying degrees of experience in their profession. ${ }^{10}$ Recent graduates are able to share their insight into their recent employment experiences which can be beneficial to current students. ${ }^{15}$ A guest speaker may also be invited as a way to give them insight into the academic institution when that individual qualifies to join the program faculty. This approach benefits both the guest speakers and the program by creatively orientating speakers to be future faculty members and strategically integrating individuals with rich practical experiences into an academic world. ${ }^{12}$

Academic guest speakers are important resources for professors and students as they can help with knowledge gaps, especially when a discipline is vast. ${ }^{16}$ Academic guest speakers who are experts in their disciplines may come from other faculties or other universities. ${ }^{12,16}$ For example, experts from the campus placement office can be invited to present in the teaching units on employmentrelated communication. Professionals from the department of computer sciences can be invited to converse on communication technology. International students and representatives of the university research and development center can be invited as guest speakers pertaining to multicultural communication. ${ }^{11}$ Using guest speakers at one's own academic organization is a cost-effective approach to promote interprofessional education.

It is necessary for professors to have a list of potential speakers. When speakers perform well in class, they should be invited back in future semesters. ${ }^{15}$ One educational institution chose guest speakers through a database where they recorded potential speakers or organizations that they could invite to their classes. This list included former students, national professional boards, societies, alumni directories, organization listings, other faculty members, and organizations that hire program graduates or suggested by students. The database kept a record of each individual's affiliations, job title, expertise, and contact information. ${ }^{10}$ Having a database decreases the work of selecting future guest speakers and can promote better teaching outcomes.

\section{What: content and benefits What speakers should present about?}

The topic of the guest's lecture should be specific and should relate to the course objectives. ${ }^{15}$ The professor should review potential topics with the speaker prior to the presentation. ${ }^{15}$ Professors can encourage guest speakers to use their "war stories" to tie in their experience with course objectives or important theories. ${ }^{1,12}$ Speakers can discuss the reality of their career or industry, local practice issues, sociopolitical tensions, or controversial topics. $^{12,17,18}$ Guest speakers can be used to engage students in topics that they may not be interested in. For example, if a speaker from a political field is brought in to a class, it could lead to increased civic participation amongst students. ${ }^{13}$ A speaker can also be used in nontraditional ways to present different content. Some examples would be guest speakers bringing an industry problem to the class to solve and then evaluating the process; carrying out mock interviews with students and giving constructive feedback; or having students submit anonymous questions to the guest, who responds with their perspective. ${ }^{15}$ Guest speakers should be sensitive to culture, gender, and current social issues.

\section{What benefits can be gained by incorporating guest speakers?}

By including guest speakers, educational relationship changes from bilateral between students and professors to trilateral among students, professors, and guest 
speakers. In addition, involving guest speakers promotes reciprocal benefits, where guest speakers, students, and professors have dual roles and contribute to and gain from each other.According to summaries of existing literature, a Trilateral Model of Benefits was created (Figure 2).

Guest speakers infer benefits for students by preparing them for job interviews and providing counseling on career issues. Importantly, guest speakers can provide students with jobs and internships because of the new partnerships with the school. ${ }^{10,12,19}$ Guest speakers also benefit from the trilateral relationship. Speakers have the opportunity to work closely with students, allowing them to scout out potential recruits. Additionally, students give guest speakers thank you notes and constructive feedback on their presentation which is helpful to their professional development. ${ }^{12,16}$ Guest speakers are also benefited through working with professors. Guest speakers build a relationship with the school and receive a thank-you card, stipend, or gift for speaking. ${ }^{12,16}$

Professors infer benefits on their students when they use guest speakers by giving students an opportunity to network, enhance their learning, increase the uptake of course content, and create new meaning through the guest speakers. ${ }^{1,10,12,19,20}$ Professors also benefit from including guest speakers in their classes. Professors are able to obtain backing from organizations and financial support for schools through their relationship with their guest speakers. ${ }^{12}$ Guest speakers can also model behaviors that students need to learn but are not comfortable with, for example, public speaking. ${ }^{11}$ Furthermore, guest speakers can reinforce what the professor has taught in the past, leading to an enhanced credibility from the perspective of students. ${ }^{1,12}$

\section{When: timing}

\section{When should guest speakers be invited?}

A speaker should be invited to give a lecture with advanced notice. ${ }^{15}$ It is helpful connecting with the speaker before the semester has started and following-up the day before the lecture to ensure attendance. ${ }^{10}$ Professors can discuss the course objectives and assignments with the speaker ahead of the guest lecture. ${ }^{12}$

\section{How long should the lecture be?}

Although most papers did not discuss how long a guest lecture should last, one discussed ideas on the length of lectures when it came to nontraditional uses of guest speakers. In this exploratory study, guest lecture format was selected based on student feedback to have between two to four guest speakers during one class, promoting diversity in the perspectives that were shared. These lectures were scheduled in a 2- to 3-hr class block, began with a 15-min question period for the speakers, and was followed by students in smaller groups rotating between the guest speakers for $10-20$ mins per guest. ${ }^{10}$

\section{Where: setting}

Traditionally, guest speaker events have been held in classrooms and allow students to interact with speakers in the same time and place. ${ }^{1}$ Students reported that the guest enhanced their education and expanded their understanding of the work climate. ${ }^{21}$ In a postevent survey, $95 \%$ of students provided positive responses to inviting another guest in the future. ${ }^{10}$

While guest speakers are constantly invited in classroom settings, online guest speaker events are growing dramatically due to new technology. Compared with the traditional classroom use of guest speakers, virtual guest lectures occur online and do not have time or geographic barriers. $^{1,14,22}$ Utilizing online technology to facilitate guest speakers also allows for a larger pool of potential speakers. ${ }^{14,22}$ Online guest speaker events can be in various formats, such as through webcasts, ${ }^{22}$ discussion platforms, ${ }^{1,23}$ and video chats. ${ }^{14}$ Online guest speaker presentations can be taped to capture the dialogue of students with the guest, and later be used as a reference for assignments or exams. ${ }^{1}$ It should be noted, however, that professors need to look into legal guidelines for recording guest speakers and students. ${ }^{14}$ An empirical study found that students accepted online discussions shown by their request for additional online discussions, as they appreciated the interaction with the speakers who shared experiences and expertise. ${ }^{18}$

\section{How: process}

A flow model of using guest speakers ${ }^{12}$ has been articulated. This model consists of seven steps including initial approach, determining the goals for a guest speaker event, sharing course materials with the speaker, preparing the audiences, preparing for coming event, and gathering and providing feedback to the speaker. This study did not come across information regarding university and department policies and criteria surrounding inviting guest speakers, which will need to be explored in further studies. 


\section{How to prepare for a guest speaker event?}

Preparation is an important part of utilizing guest speakers appropriately and applies to both the guest and students. Professors can discuss course objectives, assignments, and the syllabus with the guest ahead of time. ${ }^{12}$ To prepare a guest for their lecture, professors can send a letter to the guest regarding the selection of a topic, length of the class, available technology, and time for questions. Guest speakers should be told that silence is normal and may occur during parts of the lecture, and that they should not have a strict script, but rather speak more freely with students. ${ }^{15}$ Guest speakers can be encouraged to utilize different visual aids, such as PowerPoint, handouts, or video clips. ${ }^{12}$ To help prepare guest speakers further, professors may choose to give the speaker a reflection question to facilitate group discussion. This question serves to ease the preparation work for the speaker and promote interactions with students in speaker event. ${ }^{19}$ Guest speakers can also be encouraged to begin their lecture by stating the importance of the topic they are presenting to obtain buy-in from students. For example, a guest might discuss how the material is linked to employment, tell a personal anecdote, or discuss a historical example related to the topic they are speaking on. ${ }^{24}$

It is also important to prepare students for the guest speaker events ahead of time. Students should either be given a brief description of the guest speakers and their experience, or be required to independently research them preceding the event. ${ }^{10,12}$ Some professors also choose to have students come up with questions for the guest ahead of time, and then send them to the guest to provide an overview of what students are interested in. Additionally, the students can prepare for a guest speaker by brainstorming what they want to take away from the guest lecture. ${ }^{10}$ Students can be given the option to have refreshments with the speaker after the event. This has been suggested as an effective approach to engage students in the guest speaker event $^{10}$

\section{How to incorporate in-classroom activities in guest speaker events?}

Although the most common format of a guest speaker event is lecture and presentation, speakers can also be used creatively in classes through different approaches. For example, multiple speakers could be invited during one classroom section. The class could begin by having speakers introduce themselves and taking questions from students. Then, students rotate through the different speaker stations in small groups. ${ }^{10}$ Alternatively, a professor could have guest speakers give students a problem from their field at the beginning of the semester and evaluate the students' work at the end of the semester. Speakers could also perform mock interviews for students. ${ }^{15}$

Another consideration during a guest speaker event is whether or not students should be tested on the content guest speakers presented. Some experts believed that classes with guest speakers should not be mandatory to create a positive atmosphere where the students wish to attend. ${ }^{24}$ Contrary to this opinion, an empirical study was conducted to determine if making guest lectures mandatory and telling students they would be tested produced different results than telling students they would not be tested. Although both the tested and nontested group did not want to be tested on the guest speaker content, the results showed that the group that was told they were being tested had increased recall of the material presented by the speaker, rated the guest speaker higher and the lecture more worthwhile, took more notes, paid greater attention, and had more interest in having future guest speakers. $^{21}$

\section{How to follow-up after a guest speaker event?}

The process of using a guest speaker does not end with their lecture. Following the speaker's presentation, the material presented by the speaker can be used in the students' course work. For example, a professor assigned students to write a five-page paper after their online discussion to link the content from the guest speaker to the course material. ${ }^{1}$ Another innovative approach is to have students write a reflection about what they learned from the lecture, which can be anonymized and sent to the guest for feedback. ${ }^{19}$ It is suggested that guest speakers receive feedback from students through evaluation mechanisms. ${ }^{12,15}$ Additionally, it is important to give guest speakers thankyou notes which describe the appreciation from the inviters and could be included in a guest speaker's professional portfolio. ${ }^{12}$ Guest speakers can also be given a small memento, stipend, or gift from the school to strengthen the relationship with the guest. ${ }^{12,16}$

\section{Discussion}

Existing literature has provided anecdotal experiences, expert opinions, and exploratory studies on using guest speakers in both classroom and online teaching settings. Findings suggested the general principles on who should 


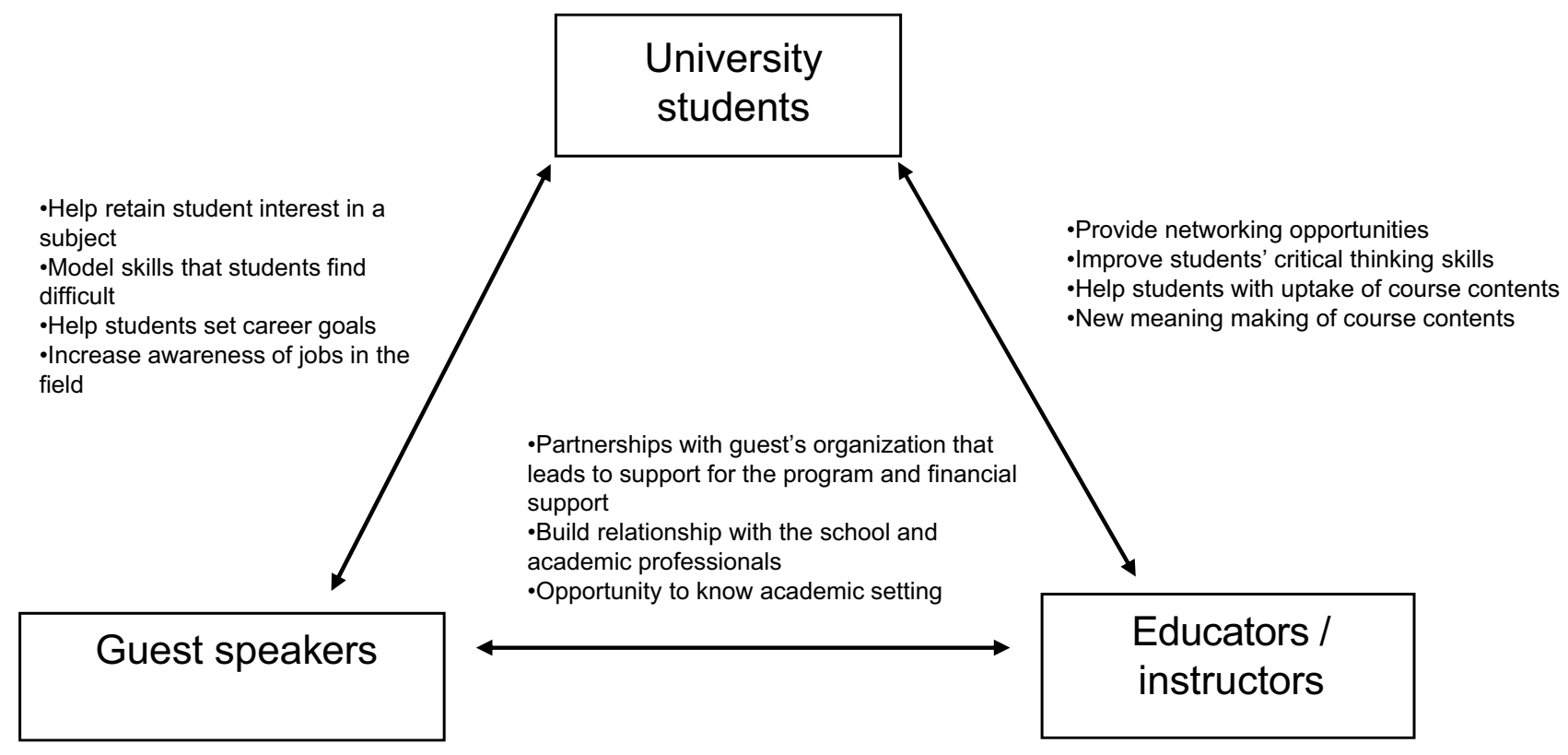

Figure 2 Trilateral model of benefits of using guest speakers.

invite or be a guest speaker, what should guest present about, where should guest present, when should guest speakers be used, and how should guest speakers be used. The literature also indicated that guest speaker events were well received by students and might have potential effects on professional development. However, 18 papers came from disciplines with a large variety, which makes the knowledge translation in a specific discipline difficult. In addition, there is lack of studies on the educational outcomes of using guest speakers with appropriate measurements of reliability and validity.

Nursing education can be considered as a branch from general education discipline. Thus, general rules of using guest speakers are applicable to nursing education. The selection of guest speakers should be considerate to the unique aspects of nursing education which includes a wide variety of learning activities in different settings. Following the $5 \mathrm{Ws}$ framework, this paper suggests inviting the right people from the right place to present the right content in right professional manners in order to produce right educational outcomes. (a) Right people. Since nursing is a practice profession, staff nurses and bedside nurses should be considered as essential guest speakers who can share clinical skills and nursing values to students. When considering nursing guest speakers, titles and positions should not override clinical experiences. (b) Right place. A variety of clinical settings should be stressed to provide students with sufficient exposure to different nursing roles. (c) Right content. Guest speakers can present course content with extended knowledge in their specific fields. (d) Right professional manner. (e) Right educational outcomes. Expected outcomes should be listed in the guest speaker invitation and teaching plan. A proper evaluation form should be developed to evaluate the performance of a guest speaker. In addition, future research needs to explore the process of developing evaluation forms to assess guest speaker performances, such as what are evaluation criteria, who generates the evaluation criteria, and who should complete the evaluations. Evaluations should incorporate different panels including students, the instructor, and the guest speaker themselves, in order to capture different perspectives regarding the use of the guest speaker.

Based on existing literature, a Trilateral Model of Benefits was created (Figure 2). This model suggests that win-win-win relationships existed in trilateral partnerships. Thus, when relationships are built between students, guest speakers, and educators, it is important to pay attention to balance the benefits and contributions of different partners. Involving guest speakers may promote innovation pedagogy where students as important stakeholders are able to actively participate in the learning process. At the same time, guest speakers can be the potential partners to educational institutions and facilitate the reciprocal knowledge translation between classroom and practice. 
While online guest speaker events have been recognized as an emerging phenomenon, there is a lack of quantitative study to properly measure outcomes. Most of the papers either are expert opinions based on anecdotal experiences or had small sample sizes. ${ }^{20,23}$ Most of the articles were $>10$ years old, of which findings, such as lack of access to webcasts, are unrelated to current practice. ${ }^{22,23}$ Future research should reflect the use of current technology and rigorous research design with appropriate sample size and aim to measure related outcomes.

Research on the application of guest speakers in nursing education is a relatively new field to explore. Existing studies from other disciplines can be referred, but knowledge translation from other fields should be carefully examined in future studies. First, due to characteristics of nursing discipline and its education programs, qualitative study to explore the experiences of students, guest speakers, and faculty in guest speaker events should be the starting point of future study. Importantly, there is a lack of studies regarding the guest speakers' experiences in current research. As one of the important partners in the trilateral relationships, understanding guest speakers' experiences might improve their active participation and enhance the education outcomes of guest speaker events. Second, while a flow model of using guest speakers in the tourism and hospitality discipline ${ }^{12}$ has been articulated, further research is needed to adapt and test the feasibility and effectiveness in different contexts of nursing education. The roles of faculty, guest speakers, and students in the model need to be further clarified. Third, outcomes of using guest speakers on nursing education need to be examined using rigorous designs. Among existing evidence in non-nursing disciplines, a qualitative study ${ }^{17}$ and a small sample size cross-sectional study ${ }^{19}$ suggested potential positive outcomes of guest speakers, especially in students' professional development, but a quasi-experimental study was unsuccessful in determining these outcomes. ${ }^{25}$ It is necessary to start with exploratory descriptive studies to explore the possible outcomes of using guest speakers in nursing education. Then, quantitative designs, such as pre and posttest or randomized controlled trials, are needed to measure and determine the expected outcomes.

Some limitations existed in this integrative review. There was a lack of substantial research on using guest speakers on nursing education. There were also limited findings regarding evaluations of guest speaker performances by guest speakers themselves regarding their experiences, policies, and procedures they had to follow, and compensation. The search terms used brought up studies that were concentrated in the United States of America, which warrants the need to expand research to different countries and regions, especially because multiculturalism is an important aspect of nursing education and nursing practice. Additionally, some methodology limitations existed within studies, such as low response rate in a cross-sectional survey and mainly qualitative design., ${ }^{2,3}$ These limitations bring up the need to conduct further qualitative and quantitative research in order to enhance and understand the relationship between guest speakers, educators, and students.

To conclude, inviting guest speakers in higher education is an intervention that benefits students, educators, and guest speakers, which can be described through a trilateral relationship in which all groups can enhance the teaching and learning outcomes of each other. Utilization of a guest speaker in nursing education can be especially beneficial by closing knowledge gaps university educators are not able to; sharing meaningful career and personal experiences; and building connections among schools, faculties, students, and organizations. With the influences of technological advances in higher education, guest speakers are not limited to having to be physically present, with virtual guest speakers becoming more prevalent. Further research and study are warranted within the discipline of nursing to produce findings directly applicable to nursing education that will help inform best possible practices and procedures regarding the use of guest speakers in nursing education.

\section{Disclosure}

The authors declare that the have no conflicts of interest in this work.

\section{References}

1. Eveleth DM, Baker-Eveleth LJ. Student dialogue with online guest speakers. Decis Sci J Innovative Educ. 2009;7(2):417-421. doi:10.1111/dsji.2009.7.issue-2

2. Sortedahl CK, Imhoff $\mathrm{H}$. Perspectives from the field: bringing nurse leaders into the classroom. Nurs Educ Perspect. 2016;37(2):113-114.

3. Strickland K, Gray C, Hill G. The use of podcasts to enhance research-teaching linkages in undergraduate nursing students. Nurse Educ Pract. 2012;12(4):210-214. doi:10.1016/j.nepr.2012.01.006

4. Hudson-Barr D. From research idea to research question: the who, what, where, when, and why. J Spec Pediatr Nurs. 2005;10(2):90-92. doi:10.1111/j.1744-6155.2005.00014.x

5. Burtonshaw-Gunn S. The Essential Management Toolbox: Tools, Models and Notes for Managers and Consultants. Chichester (England): John Wiley and Sons Ltd; 2009.

6. Smith R, Sidhu R, King D, Skelsey D. The Effective Change Manager's Handbook. London (UK): Kogan Page; 2014. 
7. Jayapandian CP, Zhao M, Ewing RM, Zhang GQ, Sahoo SS. A semantic proteomics dashboard (SemPoD) for data management in translational research. BMC Syst Biol. 2012;6 Suppl 3:S20. doi:10.1186/1752-0509-6-S3-S20

8. Moher D, Liberati A, Tetzlaff J, Altman DG. Preferred reporting items for systematic reviews and meta-analyses: the PRISMA statement. J Clin Epidemiol. 2009;62(10):1006-1012. doi:10.1016/j. jclinepi.2009.06.005

9. Critical Appraisal Skills Programme. CASP checklists; 2017. Accessed December 20, 2018. Available from: http://www.casp-uk. net/casp-tools-checklists

10. Metrejean C, Pittman J, Zarzeski MT. Guest speakers: reflections on the role of accountants in the classroom. Accounting Educ. 2002;11 (4):347-364. doi:10.1080/0963928021000031466

11. Nourse ME. Tapping campus talent for the collegiate business communication course: a guide to guest speakers. Bus Commun $Q$. 1995;58(2):25-27. doi:10.1177/108056999505800205

12. McCleary KW, Weaver PA. The effective use of guest speakers in the hospitality and tourism curriculum. J Teach Travel Tourism. 2008;8 (4):401-414. doi:10.1080/15313220903152910

13. Hess D. Beyond guest speakers. Social Educ. 2004;68(5):347-348.

14. Sage M. Distance guest speakers in online synchronous classrooms: practical and legal considerations. J Teach Social Work 2013;33(4-5):385-392. doi:10.1080/08841233.2013.831802

15. Cloud B, Sweeney J. Effective guest speakers require thought and care. J Educ. 1988;42(4):30-31. doi:10.1177/107769588704200412
16. Wetzel RD. Contacting guest speakers. J Phys Educ Rec Dance. 2012;83(6):51-53. doi:10.1080/07303084.2012.10598797

17. Farruggio P. The effect of a virtual guest speaker in expanding the consciousness of bilingual education teachers preservice during an online discussion. Int $J$ Instr Media. 2011;38(2):169-175.

18. McRee A-L, Madsen N, Eisenberg ME. Guest speakers in school-based sexuality education. Am $\quad J \quad$ Sex $\quad$ Educ. 2014;9 (2):205-218. doi:10.1080/15546128.2014.903816

19. Zorek JA, Katz NL, Popovich NG. Guest speakers in a professional development seminar series. Am J Pharm Educ. 2011;75(2):28.

20. Farruggio P. Bilingual education: using a virtual guest speaker and online discussion to expand latino preservice teachers' consciousness. Multicultural Educ. 2009;17(1):33-37.

21. Hite RE, Bellizzi JA, Dietvorst DS. Test-expectancy influence on student learning and evaluations of guest speakers. J Mark Educ. 1985;7(2):60. doi:10.1177/027347538500700209

22. Bell S. Cyber-guest lecturers: using webcasts as a teaching tool. TechTrends. 2003;47(4):10-14. doi:10.1007/BF02763506

23. Hemphill LS, Hemphill HH. Evaluating the impact of guest speaker postings in online discussions. $B r J$ Educ Technol. 2007;38 (2):287-293. doi:10.1111/bjet.2007.38.issue-2

24. Badia G. Listen up, everyone! Conquering students' inattentiveness when you're the guest lecturer. Issues Sci Technol Librarianship. 2015;spring(80):6.

25. Mooney LA. Pitching the profession: faculty guest speakers in the classroom. Teach Sociol. 1998;26(3):157-165. doi:10.2307/1318829
Advances in Medical Education and Practice

\section{Publish your work in this journal}

Advances in Medical Education and Practice is an international, peerreviewed, open access journal that aims to present and publish research on Medical Education covering medical, dental, nursing and allied health care professional education. The journal covers undergraduate education, postgraduate training and continuing medical education including emerging trends and innovative models linking education, research, and health care services. The manuscript management system is completely online and includes a very quick and fair peer-review system. Visit http://www.dovepress.com/testimonials.php to read real quotes from published authors. 